\title{
El uso de redes sociodigitales en las protestas de los Malnacidos en Hermosillo, Sonora, 2013
}

\author{
The Use of Social Media in Malnacidos' Social Protests \\ in Hermosillo Sonora, 2013
}

\author{
Isaac de Jesús Palazuelos Rojo*
}

\section{Resumen}

El objetivo de este artículo es reflexionar en torno a la protesta social contemporánea y su vínculo con el uso de redes sociodigitales. Se presenta un estudio de caso a partir de una reseña de manifestaciones del movimiento social llamado Malnacidos en Hermosillo, Sonora. Plantea un método de etnografía digital mediante la consulta de archivos audiovisuales de Facebook y YouTube. Los resultados mostraron que los entramados de interacciones digitales estimularon la emergencia de un sujeto colectivo que se opuso al paquete fiscal de la entidad emitido en 20I3. También se encontró que el movimiento se caracterizó por tipificaciones diferenciadas, las cuales dieron lugar a negociaciones entre ciudadanos y representantes de los poderes ejecutivo y legislativo. Concluye que determinados actores políticos también formaron parte de las acciones reivindicativas. Frente a este hallazgo, el estudio presenta la limitación de haberse enfocado únicamente a la dimensión ciudadana.

Palabras clave: sujetos sociales; movimientos sociales; protesta social; redes sociales (en línea); redes sociodigitales; ciberactivismo; Malnacidos.

https://orcid.org/0000-0001-8150-9201

Cómo citar: Palazuelos Rojo, I. J. (2019). El uso de redes sociodigitales en las protestas de los Malnacidos en Hermosillo, Sonora, 2013. región y sociedad, 31, el 226. doi: I0.22198/rys2019/31/I226

*Universidad Durango Santander. Carretera internacional a Nogales Km. 9.8, Café Combate, C. P. 83165, Hermosillo, Sonora, México. Correo electrónico: isaac.palazuelos@gmail.com

Recibido: 14 de junio de 2019

Aceptado: 18 de octubre de 2019

Liberado: 27 de noviembre de 2019

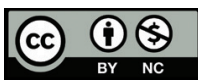

Esta obra está protegida bajo una Licencia

Creative Commons Atribución-No Comercial 4.0 Internacional. 


\section{Introducción}

En las últimas dos décadas se han llevado a cabo protestas y conflictos sociales que han usado las redes sociodigitales. A escala internacional, los eventos más sobresalientes son el conjunto de protestas por la democracia, en contra de regímenes autoritarios en el norte de África en 2011, conocidas como "la primavera árabe". En tal contexto, el uso de medios digitales de comunicación se ha debatido ampliamente (Varón, 2012).

Otro caso sobresaliente fue el 15M en España, también en 2011, mediante el cual los ciudadanos reclamaron un tipo de democracia más abierta y participativa. De acuerdo con Bonet (2011), previo a las manifestaciones públicas, los movimientos que se unieron a esta lucha colectiva se organizaron y realizaron una labor informativa a través de Facebook y de diversos blogs, con el fin de evitar la improvisación durante las ocupaciones del espacio público. Otros autores, como Toret et al. (2013) y Treré y Barranquero (2018), emplean el término "tecnopolítica" para el estudio de las movilizaciones sociales vinculadas al uso estratégico de medios digitales en la organización y acción colectiva.

En México también se han producido manifestaciones sociales similares. En éstas ha sido central la utilización de las redes sociodigitales, tanto para el desarrollo del movimiento como para la reivindicación de los derechos universales. El año 2012 se distinguió por presentar diferentes demandas y expectativas ciudadanas. El proceso electoral y el cambio de administración federal se hicieron notar principalmente a través del movimiento \#YoSoy132. De acuerdo con Morales (2014), dicho movimiento se expandió a raíz de la publicación de diversos videos en YouTube que mostraban la confrontación entre estudiantes y el entonces candidato a la presidencia de la república Enrique Peña Nieto durante su visita a la Universidad Iberoamericana.

Si bien las manifestaciones nacionales surgidas en el ámbito político a partir de las redes sociodigitales mostraron un poder significativo en el alcance de escuchas y de seguidores del movimiento \#YoSoy132, también lo hicieron otras luchas en las que el uso de dichos medios fue relevante. Un ejercicio regional corresponde a las protestas en contra del impuesto a tenencia vehicular en Sonora, en las cuales el uso de dichas redes fue central, como se explicará más adelante.

El llamado movimiento de los Malnacidos tuvo presencia en Sonora durante los años 2012 y 2013 como una forma de protesta en contra del pago del impuesto a la tenencia vehicular. Moreno (2013) relata que el domingo 13 de enero apareció el apelativo de malnacidos en una manifestación, debido a que durante una conferencia de prensa, ocurrida el 10 de enero de 2013, el entonces gobernador de Sonora, Guillermo Padrés, nombró “no bien nacidos” a los ciudadanos involucrados en las protestas en contra del impuesto. Esta percepción de peligro y descrédito para con los protestantes dio lugar a la posibilidad de boicotear la Serie del Caribe de béisbol, que se celebraría del 1 al 7 de febrero del mismo año en Hermosillo, capital de la entidad. 
El impuesto a la tenencia vehicular se creó en México algunas décadas atrás. Según Esquivel (2011), la creencia general es que a efectos de generar un nuevo ingreso fiscal temporal como apoyo al financiamiento de los juegos olímpicos de 1968, se estableció el cobro del impuesto durante el gobierno de Adolfo López Mateos el 28 de diciembre de 1962. Sin embargo, el comité olímpico no declaró al país como sede oficial del magno evento deportivo sino hasta el año de 1963, lo cual desacredita esta creencia (Esquivel, 2011).

La supuesta provisionalidad del impuesto se extendió durante más de cuatro décadas, pues dicho cobro quedó legitimado como medio de recaudación fiscal. El 4 de julio de 2011, el entonces presidente de la república, Felipe Calderón Hinojosa, anunció la eliminación de la obligatoriedad del impuesto a escala federal y dejó en manos de las legislaturas estatales la decisión última de derogar o no la tenencia vehicular en cada una de las entidades federativas (Ramos, 2011). El 15 de noviembre de 2012 se publicó en la página del Congreso de Sonora la recepción de la iniciativa de ley del ejecutivo sobre el paquete fiscal de 2013, el cual fue aprobado por los diputados el 13 de diciembre del mismo año. ${ }^{1}$

El rechazo y la indignación de los ciudadanos sonorenses no tardaron demasiado en manifestarse. Los afectados salieron a las calles en múltiples movilizaciones como gesto de protesta. Según Rosagel (2013), hasta ese momento los ciudadanos de esa entidad nunca se habían unido con tal fuerza para protestar en contra del gobierno. Señala que estas movilizaciones superaron en número las protestas por el incendio en la Guardería $A B C .{ }^{2}$ Dichos acontecimientos adquieren relevancia analítica, porque las protestas se extendieron con gran velocidad a lo largo de las ciudades más importantes del estado. Se integró una población heterogénea de varios sectores sociales, que convencionalmente no suelen involucrarse en protestas o manifestaciones públicas, a partir de una labor de difusión y organización en las redes sociodigitales.

Esta investigación partió del supuesto de que el movimiento de los Malnacidos había revelado la emergencia de sujetos que se expresaron a través de un conjunto de protestas particulares que, por medio del uso de las redes sociodigitales, adquirió fuerza. Se abordaron dos aspectos generales: 1) los repertorios de acción de los Malnacidos con el objetivo de derogar el impuesto a la tenencia vehicular; 2) el uso simultáneo de redes sociodigitales, como Facebook y YouTube, en la organización del movimiento y en la difusión de in-

1 En el documento "Exposición de motivos e iniciativa de ley", en el capítulo $V$ del impuesto sobre traslación de dominio de bienes inmuebles y del impuesto sobre capitales, sección primera, artículo 188, segunda parte, inciso b), y en la sección tercera "Contribución al Fortalecimiento Municipal" (COMÚN), artículo 212, se establece que todos los propietarios de vehículos, cuyos modelos sean de hasta diez años anteriores a la fecha, deberán pagar impuesto. http://transparencia.esonora. gob.mx/Sonora/Transparencia/Poder+Ejecutivo/Entidades/Instituto+Sonorense+de+la+Mujer/ Presupuesto/

2 El cinco de junio de 2009 ocurrió un incendio en la guardería de nombre ABC, ubicada en HermosiIlo, Sonora. En el incidente perdieron la vida 25 niñas, 24 niños y alrededor de 70 más sobrevivieron con lesiones físicas, respiratorias y de corazón. Desde el incidente, familiares de las niñas y de los niños afectados, así como parte de la sociedad civil, se han movilizado en múltiples acciones de protesta por el reclamo de justicia, buscando responsabilizar a los dueños de la guardería y a ex funcionarios involucrados en los tres niveles de gobierno. 
formación (Mattoni, 2013). Se utilizaron estas dos vertientes para reflexionar en torno a los procesos de subjetivación, ${ }^{3}$ así como sobre las expresiones particulares de un contexto en el que las interacciones digitales tienen un papel social relevante. Se plantearon dos objetivos: 1) estudiar el uso de las redes sociodigitales en un conjunto de protestas regionales en contra del impuesto a la tenencia vehicular, a fin de comprender la emergencia de sujetos sociales en el movimiento que se denominó Malnacidos, en Hermosillo, Sonora, durante 2012 y 2013; y 2) estudiar en qué sentidos las interacciones digitales fueron capaces de impulsar la emergencia de sujetos y favorecer procesos de subjetivación.

\section{Metodología}

El estudio se elaboró a través de tres ejes de análisis: 1) el concepto de sujeto, con el cual se abordaron las protestas como un proceso de subjetivación que rechaza la imposición del Estado sobre los ciudadanos, a la vez que los ciudadanos manifestaron el deseo de ser reconocidos como sujetos de derecho, con voluntad y autonomía propias; 2 ) el referente de movimiento social es el punto de partida para el análisis, con la intención de identificar los objetivos de los manifestantes, la forma en que definen a sus adversarios, el desarrollo de sus repertorios, campañas y demostraciones WUNC (worthiness, unity, numbers, and commitment); ${ }^{4}$ y 3 ) el uso de las redes sociodigitales en la organización de protestas y en la difusión de información.

Se utilizó la etnografía digital (Pink, Horst, Postill, Hjorth, Lewis y Tacci, 2016) como herramienta metodológica de carácter cualitativo, para vincular la exploración de espacios de interacción digital con otros contextos y eventos sociales, en este caso la disputa política. La etnografía digital integra otras estrategias de recolección de datos, como la entrevista en profundidad. Además, aplica algunos aspectos de la etnografía tradicional al estudio de las interacciones en las redes sociodigitales, espacios públicos en internet e información disponible para el estudio de fenómenos sociales vinculados con experiencias digitales de interacción (Pink et al., 2016).

Si bien existen otros antecedentes de etnografía virtual, como la desarrollada por Hine (2004), decidimos utilizar el marco metodológico propuesto por Pink et al. (2016), ya que estos autores establecen un enfoque holístico, en el que la etnografía digital no se hace exclusivamente desde las redes, sino que incluye el estudio de los contextos sociales, políticos y culturales en los que tienen lugar los fenómenos estudiados, estableciendo contacto con los sujetos, principalmente a través de la entrevista.

3 Para Touraine (2011), la subjetivación es un proceso en el que los individuos experimentan cambios en las formas en que se observan a sí mismos y a los demás. Esta observación está orientada a descubrir una capacidad de convertirse en actores y agentes de cambio del contexto social.

4 De acuerdo con Tilly (2010), las demostraciones WUNC son una serie de expresiones en las que se pueden observar el valor moral de los manifestantes, su unidad en términos simbólicos y de identidad colectiva, la cantidad de personas sumadas al movimiento social y el compromiso que éstas desarrollan para con los objetivos de la reivindicación. 
Se analizaron los contenidos del perfil de Facebook llamado "No a la tenencia en Sonora". ${ }^{5}$ Tenía 22783 miembros y sus publicaciones se extendieron desde inicios de la protesta, en diciembre de 2012, hasta finales de 2015. En paralelo, se analizó la fan page de "No a la tenencia en Sonora" ${ }^{6}$ utilizada por los Malnacidos durante las protestas. Esta página tenía 140234 seguidores. En ambos casos, se estableció un corte temporal que abarcó desde que se abrieron los dos espacios en Facebook, en diciembre de 2012, hasta agosto de 2013, cuando las manifestaciones perdieron presencia en las calles. En tal fecha se identifica el declive de las protestas en contra de la tenencia. ${ }^{7}$

Se revisaron 45 videos sobre las protestas, las participaciones en el Congreso y las manifestaciones de los Malnacidos que los integrantes del movimiento publicaron y distribuyeron a través de YouTube. También, en 2015, se realizaron entrevistas semiestructuradas a los cuatro voceros de los Malnacidos. ${ }^{8}$ A partir de esos materiales, se construyó una cronología del movimiento con el fin de analizar las formas autónomas de comunicación y de organización de los manifestantes, en su intento para expresar sus posturas mediante el uso de las redes sociodigitales, lo que les permitió desarrollar estrategias comunicativas alternas a las desplegadas por los medios locales de noticia, así como novedosas formas de organización colectiva (Mattoni, 2013).

Con base en lo anterior, se hizo observación etnográfica de las interacciones online y de los espacios digitales utilizados por los Malnacidos. La observación se realizó durante el período en que los manifestantes ocuparon el espacio público como protesta en contra del impuesto a la tenencia. El objetivo era comprender los nuevos tipos de interacción social mediados por las redes sociodigitales, así como analizar el impacto que tales tipos de interacción tienen en los procesos de subjetivación. Es decir, se examinaron los contenidos audiovisuales - videos, memes, infografías y comentarios de internautas- para identificar elementos en las protestas que sirvieran en la comparación entre las categorías teóricas de sujeto y movimiento social y las características empíricas encontradas en las redes.

\section{Sujeto, subjetivación y desmodernización en el movimiento de los Malnacidos}

Para entender el conflicto generado en la localidad de Hermosillo a raíz de la promulgación de un impuesto, es necesario dilucidar quiénes son los acto-

\footnotetext{
https://www.facebook.com/groups/187764284694639/

https://www.facebook.com/NoALaTenenciaEnSonora/

Las características de los espacios digitales de Facebook donde se realizó la etnografía, particularmente las referidas a las cantidades de miembros y seguidores, corresponden al momento en el que se investigó el caso, que fue en 2015 , mientras que los contenidos analizados se publicaron en el período en que se dieron las protestas, entre 2012 y 2013.

8 Los voceros eran Francisco Salcido, de 54 años, licenciado en administración de empresas y vendedor de seguros; Daniel Corvera, de 54 años, jubilado, ejerció su carrera como docente de educación media; Luis Vargas, de 27 años, estudiante de ingeniería química; y Rebeca Villanueva, de 39 años, dedicada a las labores del hogar.
} 
res y cuáles las dimensiones sociales involucradas. Por un lado, se encuentran las instancias político-institucionales que dictan el orden social a través de las propuestas y de la legislación, donde un grupo reducido de actores ocupa cargos en los poderes ejecutivo y legislativo: el primero lo ocupaba el entonces gobernador de Sonora, Guillermo Padrés Elías; el segundo, los diputados de la LX Legislatura del Estado de Sonora (2012-2015). Por otro lado, se encuentran los habitantes de Hermosillo propietarios de carros de menos de diez años de antigüedad, a quienes estaba dirigido el cobro del impuesto y quienes estaban sujetos al cumplimiento de las leyes diseñadas por el primer grupo. En esta dimensión se destacan los actores que se involucraron activamente en las protestas. Acuñando los términos usados por Touraine (2006 y 2011), se puede decir que el conflicto se configuró entre dirigentes y dirigidos.

El ejercicio del ejecutivo y del legislativo como figuras institucionales, específicamente en la emisión del paquete fiscal 2013, no sólo fue incapaz de instaurar un orden; tampoco pudo ser visto como un agente eficaz y justo debido a la forma en que administraría los recursos públicos plasmada en dicho documento.

Los individuos involucrados en las protestas no respondieron de manera pasiva, ni optaron por el compromiso de asumirse como meros contribuyentes. Por el contrario, hubo en ellos y en la relación que mantienen entre sí -instituciones e individuos- una complejidad que no les permitió asumir el rol de contribuyentes en forma pasiva y por eso recurrieron a las protestas.

Touraine (2006 y 2011) plantea un esquema triangular, en el que coloca la racionalidad política y el individualismo moral en cada extremo de la base. En la parte superior ubica el Estado de derecho mediando entre las dos dimensiones. El autor da cuenta de que "no podemos creer en el triunfo final de un Estado de derecho capaz de manejar la dualidad [...] y de mantener el equilibrio entre [...] el espacio público y la vida privada" (Touraine, 2011, p. 32). La incapacidad de articular los intereses privados de los individuos con la eficacia de los aparatos sociales es una fragmentación social que se define como "proceso de desmodernización", en el que el "mundo instrumental y [el] mundo simbólico se separan" (Touraine, 2011, p. 10). El autor explica que en este distanciamiento entre espacio público y vida privada se generan diversos intereses fragmentados, de manera que la convivencia se dificulta cuando las instituciones y los habitantes tienen intereses distintos.

El conflicto causado por el cobro del impuesto a la tenencia se definió como una diferenciación de intereses dados en la fragmentación que produce el proceso de desmodernización. Tanto los funcionarios a cargo de los poderes ejecutivo y legislativo como los habitantes de Hermosillo constituyen una multiplicidad de actores diversos que interactúan en un marco fragmentado de intereses. El mundo simbólico de las identidades individuales se distancia de la racionalidad política. Mientras que los individuos exigen poner las instituciones al servicio de la comunidad y de las necesidades particulares, las instituciones intentan poner a los individuos a su servicio a través de una contribución municipal: el cobro del impuesto a la tenencia vehicular.

Los poderes ejecutivo y legislativo no existen por sí solos de manera heterónoma, sino que responden a la acción de los individuos que los animan; tampoco 
están impregnados de una racionalidad pura. Tanto el gobernador como los diputados son actores que poseen cargas simbólicas e identidades individuales. De la misma manera, los habitantes de Hermosillo involucrados en las protestas, pese a la complejidad de sus identidades, cumplen con ciertos roles sociales, a la vez que desempeñan labores o se vinculan de diversas maneras con los espacios públicos en los que se configura la vida social.

Siguiendo la propuesta de Touraine (2011), un rompimiento tan tajante entre actor y sistema es impensable. En un contexto fragmentado, en constante cambio, los individuos son capaces de establecer combinaciones entre ambos mundos en beneficio de sus proyectos de vida. Touraine (2011) define como sujeto la capacidad de articular ambas dimensiones (actor y sistema). Plantea que se trata de un atrevimiento que otorga sentido a las experiencias individuales, con el fin de favorecer un protagonismo del actor en su historia individual. Para poder transformar un contexto social en el que sistema e individuo se han distanciado, perdiendo capacidad comunicativa, debe existir un reclamo por parte de los sujetos que no toleran estar sometidos (Touraine, 2011; Wieviorka, 2011).

Esta exigencia de cumplir un deseo de individuación cuando se combinan una identidad individual con una participación en un orden social racional, esta voluntad de ser uno mismo en la combinatoria de dos mundos y en el rechazo a ser sometido por cualquiera de los dos, es lo que Touraine (2006) define como subjetivación. El autor señala que el proceso de subjetivación es una forma de proteger los derechos que favorecen las garantías individuales, es una forma de sobreponer el derecho individual al social, es pensarse a sí mismo de una forma distinta a la que imponen las normas sociales. ${ }^{9}$

En diversos comentarios plasmados en Facebook, los internautas se quejaron de la manera en que los actores políticos desubjetivaron a la población al tomar decisiones sin considerar las necesidades de la gente. ${ }^{10}$ Los internautas hicieron ver en las redes sociodigitales que la sociedad se encontraba golpeada económicamente, plasmando un rechazo tajante y evidenciando que las decisiones de los políticos desfavorecían los intereses particulares de la población.

De acuerdo con información filtrada en el perfil y en la fan page de Facebook, la administración panista pretendía realizar una condonación de impuestos a varias empresas. La suma se estimaba en setecientos millones de pesos. Los habitantes de Hermosillo se negaron a corresponderle a esta postura neoliberal, opaca en términos democráticos, que afectaba su dignidad, el derecho a la participación ciudadana y las economías domésticas.

9 Touraine (2006 y 2011) y Wieviorka (2011) entienden el sujeto como una lucha constante en contra de todas las fuerzas de dominación; es un estado indefinido de lucha, una constante negociación. El sujeto es aquel que se reconoce a sí mismo; es capaz de reconocer a los otros y de concederles su capacidad de decidir libremente. Puede ser individual o colectivo. Es en todo momento una autoafirmación. Se es sujeto cuando un individuo o una colectividad es capaz de autodefinirse en oposición a categorías impositivas e impersonales que suprimen la libertad de ser.

10 De manera inversa a la subjetivación, la desubjetivación se entiende como un proceso de cosificación en el cual no se reconoce el valor subjetivo de los sujetos y, contrario a ello, se les da un valor de cambio. En este caso, los habitantes de Hermosillo propietarios de vehículos fueron vistos como contribuyentes y no como jefes de familias con necesidades económicas particulares. 
Este rechazo es un indicador empírico válido para señalar un proceso de desmodernización en el conflicto del cobro del impuesto a la tenencia, pues se observan faltas de correspondencia entre el ejercicio fiscal y los habitantes de Hermosillo, al tiempo que es posible destacar una incapacidad, de la administración pública, de mediar entre los intereses de las vidas privadas y la eficiencia colectiva. Dicha incapacidad representó un deterioro en el Estado de derecho.

Figura 1. Proceso de desmodernización y de devenir sujeto en el movimiento de los Malnacidos

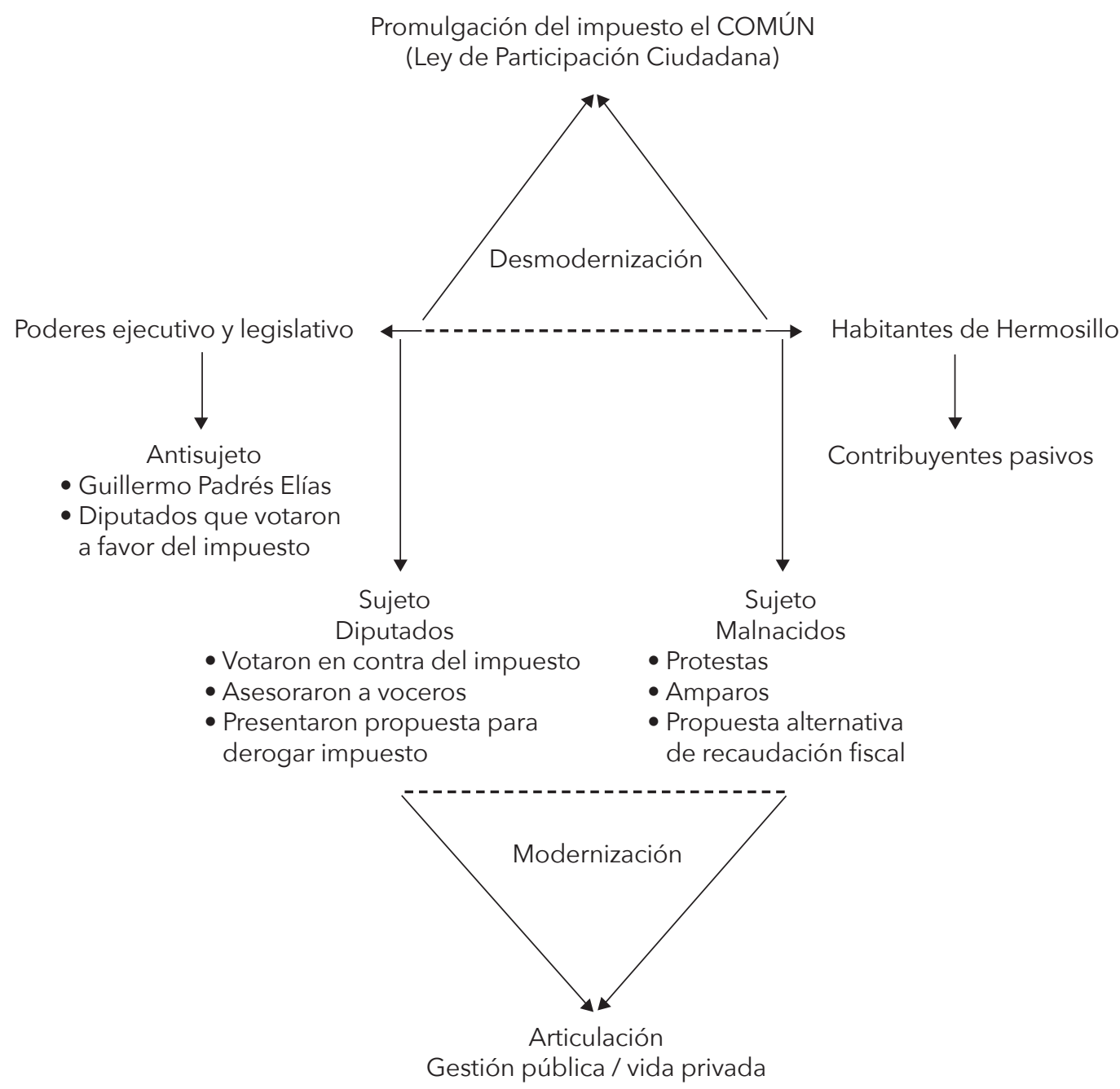

Fuente: elaboración propia con base en Touraine (2011). 
Se puede partir del citado esquema propuesto por Touraine (2006 y 2011) sustituyendo los referentes teóricos por elementos empíricos para dar cuenta del caso estudiado. En la parte superior de la figura se encuentran la promulgación del impuesto "Contribución al Fortalecimiento Municipal” (COMÚN) y la Ley de Participación Ciudadana. De acuerdo con los testimonios, se observa que la Ley de Participación Ciudadana generó un vacío en el sentir de los habitantes, pues no fueron consultados en la decisión política en el momento en que se aprobó el impuesto, al tiempo que las manifestaciones fueron reprimidas con el uso de la fuerza pública y grupos de choque. Además, la apertura al diálogo se negó de manera prolongada. Los elementos citados favorecieron el distanciamiento entre los poderes ejecutivo, legislativo y los habitantes de Hermosillo propietarios de carros.

Al lado izquierdo, en la base del triángulo, se presenta la categoría del antisujeto, en donde se enmarcan a los diputados que votaron a favor del impuesto y al ejecutivo Guillermo Padrés, quien realizó la propuesta del paquete fiscal de 2013. Siguiendo la lectura de los comentarios expuestos en Facebook por los internautas, se observó que se sintieron desubjetivados por el gobernador y por los diputados, acusándolos de ver a la gente únicamente como un valor de cambio, como un medio de recaudación fiscal, ignorando el agravio moral y las afectaciones económicas que el impuesto pudiera provocar en la población. Sin embargo, en la dimensión institucional emerge también un sujeto en los diputados que fueron capaces de reconocer a los ciudadanos, que establecieron un contacto con ellos y que actuaron legalmente en contra del impuesto.

Al lado derecho se encuentran los habitantes de Hermosillo, de donde se desprende un sector de la población que asumió el rol pasivo de contribuyente y efectuó el pago del impuesto. En la misma dimensión ciudadana se presenta otro sector de la población que se manifestó indignado y afectado económicamente por la promulgación del impuesto. Se observa la construcción de subjetividades que dan lugar a la emergencia de sujetos que, accionando de diversas maneras, ya sea desde la sociedad civil organizada, ya sea desde una función o cargo público, se mostraron capaces de combinar sus intereses individuales y su participación con un orden social racional en beneficio de su desarrollo personal y en reconocimiento de los derechos y de las voluntades de otros individuos.

\section{Campaña, repertorio y demostraciones WUNC en el movimiento de los Malnacidos}

De acuerdo con Tilly (2010), los movimientos sociales son una forma política, históricamente construida, más o menos duradera. Pueden ser de tipo programático cuando sus acciones tienen una correspondencia con los objetivos de la reivindicación; identitario cuando se construyen en torno a una identidad colectiva; y de posición cuando presentan una relación con diversos actores que ejercen cargos decisivos en el campo social en el que tiene lugar el movimiento. Según este autor, los movimientos sociales combinan de manera única, aunque 
con un cierto grado de afinidad con otros casos de reivindicación, tres características principales: la campaña, el repertorio y las demostraciones WUNC.

La campaña expresa la energía que el movimiento invierte en la esfera pública con la intención de involucrar a las autoridades en el cumplimiento de sus objetivos. Consta de tres principales aspectos: 1) los actores que se asumen como autores de la reivindicación; 2) el objeto de la reivindicación; 3 ) el público a quien se dirige; la mayoría de las veces se trata de algún tipo de autoridad (gubernamental, privada o religiosa), cuyo marco normativo y decisiones pueden afectar el estilo de vida de grandes estratos poblacionales, o bien de grupos capaces de organizar acciones reivindicativas.

El repertorio concentra las diversas acciones del movimiento, como coaliciones, asociaciones, reuniones públicas, vigilias, mítines, manifestaciones, peticiones, declaraciones y propaganda.

Las demostraciones son de tipo WUNC, sigla derivada de las siguientes palabras en inglés. Worth (valor), que tiene una connotación de conducta meritoria templada, es decir, se reconoce la participación de los sujetos involucrados en el movimiento a partir de su estatus moral, cívico y ético, estatus que a su vez es una forma de legitimar el objeto de la reivindicación. Unity (unidad), que se refiere a expresiones simbólicas capaces de generar formas de identificación entre los sujetos involucrados en el movimiento; himnos, vestuarios y símbolos son los elementos más comunes. Number (número), que se refiere a la cantidad de personas que se suman en las distintas acciones del repertorio. Y Compromise (compromiso), que explica la participación de las personas adheridas al movimiento, así como su convicción de apoyar el objeto de la reivindicación; la "resistencia ante la represión" es uno de los indicadores más visibles del compromiso (Tilly, 2010, pp. 22-23).

Partiendo de los datos obtenidos en la etnografía, se puede dividir a las personas involucradas en las protestas en cuatro grupos respecto a la autoría de la campaña reivindicativa: 1) quienes veían a los voceros únicamente como portavoces de las demandas ciudadanas; 2) aquellos que definieron a los voceros como líderes del llamado movimiento de los Malnacidos; 3 ) los que reconocían la autoría reivindicativa en el grueso de los manifestantes, pero daban mayor peso a la organización de los voceros; y 4) aquellos que daban mayor peso a la autoría reivindicativa ciudadana pero que, al mismo tiempo, reconocían la importancia de la organización de los voceros.

Siguiendo con las características de la campaña, el caso de los Malnacidos experimentó una transformación en los objetivos de su reivindicación. De acuerdo con el testimonio de Francisco Salcido, originalmente las protestas surgieron como un reclamo por el cobro de la tenencia vehicular, pero al irse involucrando el movimiento en el documento del paquete fiscal de 2013 y al darse cuenta del alza generalizada de impuestos que contenía, las protestas se asumieron como un reclamo en contra de los impuestos y por último se enfocaron en una lucha jurídica en contra de la tenencia vehicular o impuesto COMÚN. El público o adversario de la campaña reivindicativa de los Malnacidos fue el entonces gobernador Guillermo Padrés y los diputados que votaron a favor del impuesto. 
Los Malnacidos establecieron un vínculo con la Asociación Civil Sonora Ciudadana, ${ }^{11}$ de la cual recibieron orientación respecto a los procesos legislativos, al contenido del paquete fiscal de 2013 y a la delimitación de los objetivos de la reivindicación, así como a la redacción de una propuesta alternativa de recaudación fiscal. Los Malnacidos también se vincularon con el diputado Carlos Navarro del Partido de la Revolución Democrática (PRD), así como con los diputados Humberto Robles Pompa, Abel Murrieta Gutiérrez y Vernon Pérez Rubio del Partido Revolucionario Institucional (PRI).

Los diputados citados brindaron asesorías sobre los procesos legislativos, el contenido del paquete fiscal y los amparos en contra del impuesto COMÚN. Votaron en contra de tal promulgación en la sesión extraordinaria, presentaron una iniciativa de ley para derogar el impuesto, proporcionaron a los voceros información sobre fechas de sesiones en el Congreso, los invitaron a que acudieran a dichas sesiones y les brindaron asesoría respecto a las estadísticas de recaudación fiscal, así como información sobre los términos jurídicos en los que se establece el pago de tenencia y el reemplazo de placas vehiculares. ${ }^{12}$

En la mayoría de las ocupaciones del espacio público, los Malnacidos recurrían tanto a las marchas por las calles de la ciudad como a la táctica de la oratoria. Aquí las redes sociodigitales estuvieron muy vinculadas a la convocatoria de asistentes, aunque también tuvieron una labor importante a la hora de documentar y coordinar las protestas. Otro recurso peculiar del movimiento fue el uso de una pantalla en las manifestaciones, en la que se reproducían videos que mostraban las promesas de campaña del gobernador Guillermo Padrés; también se proyectaban memes, videos editados y otros contenidos audiovisuales que circulaban en las redes sociodigitales como parte de sus repertorios comunicativos (Mattoni, 2013).

Desde las redes socioculturales convocaron y coordinaron, mediante la distribución de referencias geográficas y de tránsito, la realización de caravanas de automóviles, en las que los integrantes del movimiento se manifestaron en contra de la tenencia vehicular, haciendo uso de sus vehículos particulares para transitar sobre los principales bulevares de la ciudad. De manera estratégica, a través de Facebook, compartían la geolocalización de los puntos de acceso bloqueados por la policía, con el fin de evadir las rutas resguardadas y poder sumarse a las caravanas.

Se realizaron múltiples vigilias en el Congreso estatal, pues una parte del movimiento tenía la responsabilidad de estar pendiente del calendario de sesiones, de manera que acudió para informarse y ejercer presión. El movimiento también redactó un pliego petitorio que incluía la apertura al diálogo con el Ejecutivo, así como una sesión extraordinaria en el Congreso para votar nuevamente el paquete fiscal de 2013. Solicitó, además, que la propuesta alternativa de recaudación fiscal fuera considerada y analizada en el pleno y que se eliminara o con-

11 La Asociación Civil Sonora Ciudadana se define a sí misma como: "una organización civil no gubernamental, independiente y apartidista dedicada, desde el ámbito local, a la defensa y promoción de los derechos humanos a favor de construir una democracia integral en México". Esta organización desapareció a mediados de 2018.

12 El presente análisis podría ampliarse con la entrevista a los diputados mencionados. Sin embargo, se limitó al estudio de la dimensión ciudadana. 
donara el impuesto. Se hicieron algunas declaraciones a los medios. Muchas se realizaron al término o durante las manifestaciones; otras fueron programadas.

Respecto a las representaciones WUNC, Luis Vargas relató que el apelativo de malnacidos fue uno de los elementos que generó mayor unidad de grupo entre los manifestantes. Rebeca Villanueva señaló que portar la camiseta con el logotipo de "Soy sonorense malnacido" generó también gran afinidad. Los cuatro voceros señalaron que el concepto de sonorense malnacido debía ser interpretado como un sentir de una población que no tolera los abusos de los gobernantes, una población capaz de defender sus derechos. Por lo tanto, el apelativo de malnacidos fue uno de los elementos simbólicos más importantes en la unidad de los manifestantes.

Existieron otros elementos simbólicos, como las orejas de burro utilizadas por los manifestantes durante las marchas, los memes elaborados por los internautas, entonar el himno nacional autoafirmándose como ciudadanos patrióticos y responsables, también la canción Sonora querida entonada en algunas manifestaciones, en las que cambiaban la lírica usando la frase "Sonora qué herida", la cual cantaron durante la manifestación del 14 de agosto de $2013 .^{13}$

De acuerdo con los testimonios, las fotografías publicadas en Facebook y los videos en YouTube, en todas las ocupaciones del espacio público asistieron grandes cantidades de personas. Los voceros señalaron que a las caravanas asistieron más de diez mil vehículos. Luis Vargas relató que la importancia del número de personas involucradas en las protestas reflejaba la legitimidad que tenían sus demandas y su lucha.

Daniel Corvera destacó que el compromiso de los manifestantes se mantuvo debido a que las movilizaciones ponderaron en todo momento una actitud pacífica. Asimismo señaló que el pacifismo asumido en los repertorios de acción de los Malnacidos ayudó a legitimar la lucha. En las redes sociodigitales se observó una negativa, por parte de muchos internautas, a cometer acciones violentas. Muchos señalaron que no acudirían a las manifestaciones, principalmente a la que tuvo lugar el día de la inauguración de la Serie del Caribe de béisbol, si éstas se tornaban violentas, ya que solían asistir a ellas acompañados de sus familias, incluyendo niños y bebés.

Luis Vargas explicó que el compromiso de la gente se vio mermado tras los acontecimientos violentos provocados por grupos de choque que aparecieron en algunas de las manifestaciones, agrediendo a Daniel Corvera y a otros compañeros. El compromiso no siempre se mantuvo; hubo momentos en los que decayó. De acuerdo también con el relato de Luis Vargas, uno de los momentos de mayor decadencia en el compromiso de la gente fue cuando tres de los voceros formaron la asociación civil Sonora Transparente, ${ }^{14}$ porque esto los identificó como oportunistas. Tal idea se reforzó con la publicación de algunas fotografías de Rebeca Villanueva con el entonces presidente de la república Enrique Peña Nieto, así como con las fotografías tomadas a Guillermo Padrés con Francisco

\footnotetext{
13 https://www.youtube.com/watch?v=EW2ZGJXKJPE

14 https://www.facebook.com/SonoraTransparente/
} 
Salcido y Daniel Corvera durante la primera reunión que sostuvieron los voceros con el Ejecutivo. ${ }^{15}$

El movimiento adquirió una forma de tipo programático cuando presentó la alternativa de recaudación fiscal ante el impuesto; también con los amparos, que representaron una protección jurídica en contra del impuesto. Los Malnacidos asumieron una tipificación identitaria como movimiento social tras las declaraciones de Guillermo Padrés, cuando acusó de sonorenses no bien nacidos a las personas involucradas en las protestas. Esas personas se autoafirmaron como una identidad colectiva que luchaba en defensa de las economías domésticas y de las familias. ${ }^{16}$

Finalmente, se asumieron como un movimiento social de posición cuando establecieron afinidades y relación con los diputados del PRI y del PRD. Tomando en cuenta el testimonio de Rebeca Villanueva, tras el descenso de la ocupación del espacio público, ella y otros actores que estuvieron muy involucrados en las protestas, convocaron a la gente a votar en contra del Partido Acción Nacional (PAN) en las elecciones estatales de 2015. Según relata, nunca promovieron votos a favor de un partido; sin embargo, el voto de castigo en contra del PAN beneficiaba directamente a otras fuerzas políticas. En este sentido, los Malnacidos ya se manifestaban más como un movimiento de posición que como un movimiento programático o identitario.

\section{Uso de las redes sociodigitales en el movimiento de los Malnacidos}

Galindo (2006) explica que las redes sociodigitales se configuran en cuatro niveles de complejidad:

1) Conectividad. Parte de un reconocimiento del otro que se define por su propia distinción; establece una conexión entre individuos que genera una identidad superior.

2) Interactividad. Implica el intercambio simbólico a partir de un conocimiento mutuo.

3) Vinculación. Es el nodo donde se forman o tienen presencia los vínculos a partir de múltiples afinidades que vuelve las relaciones estrechas e incluyentes.

4) Comunicación. Este nivel de complejidad es lo que hace a las redes capaces de construir vida social, intervenirla y modificarla.

La conectividad se puede identificar en los reconocimientos que se dieron entre los integrantes de las protestas en contra de la tenencia vehicular en Sonora, así como la manera en que estas protestas pudieron formarse como un movimiento social identitario. Las interacciones digitales impulsaron la unidad entre los manifestantes, principalmente a través del uso de memes y del intercambio

15 https://www.facebook.com/photo.php?fbid=700152196712326\&set

16 https://www.youtube.com/watch?v=uxfwLGDo0Ds 
de opiniones. La vinculación lograda en el uso de redes favoreció las afinidades generadas entre los internautas involucrados en el uso de las plataformas en las que interactuaron los Malnacidos, así como las convocatorias y los mecanismos de inclusión manejados desde las redes.

El concepto de autocomunicación de masas es de utilidad para adentrarse en lo que Castells (2012) señala como un espacio de deliberación factible por el uso de una comunicación autónoma, que convierte el movimiento social en un agente de transformación. Este espacio de comunicación horizontal y autónoma dio al movimiento de los Malnacidos una capacidad transformadora del contexto social; es decir, impulsó la emergencia de los sujetos. Según relata Castells (2012), las nuevas formas de asociación derivadas del uso de internet pueden tornarse en acciones reivindicativas, debido a que las redes sociodigitales facilitan la comunicación autónoma de los individuos frente a un gobierno y unos medios de comunicación hegemónicos.

De acuerdo con este enfoque, la comunicación autónoma propicia el encuentro de individuos que comparten sentimientos, como la indignación y la esperanza. Esta coincidencia genera la creación de redes de individuos que pierden el miedo de actuar al sentirse apoyados, al sentir que no están solos, que no son los únicos que experimentan la indignación provocada por las acciones de los gobiernos. De esta manera generan conciencia para salir a las calles a protestar. La convergencia de la indignación y la esperanza en las redes sociodigitales, más la transformación de estos encuentros digitales en la ocupación del espacio público, se han venido expandiendo en diversas partes del mundo (Castells, 2012).

Según se observa en Castells (2012), lo mismo que las protestas sociales a lo largo de la historia, estas nuevas manifestaciones que se dan en las redes sociodigitales contienen un rechazo a condiciones como la pobreza, la falta de democracia en decisiones gubernamentales y la crisis económica. Sin embargo, lo que en realidad desata nuevas reivindicaciones es un sentimiento de indignación provocado por denuncias en estas redes en torno al cinismo con el que los actores políticos y empresariales toman decisiones que, lejos de favorecer el bien común, afectan la dignidad de las personas.

Para el caso del movimiento de los Malnacidos, fue significativa la posibilidad de monitorear las acciones de los actores políticos gracias al uso de redes sociodigitales. Se denunciaron los nombres y los rostros de aquellos diputados que se habían mostrado a favor del impuesto COMúN. Se dio seguimiento a sus acciones a través de la consulta de diversas páginas de transparencia y de noticias en internet. Otro aspecto significativo fue que los Malnacidos consiguieron los perfiles en Facebook, las direcciones de Twitter y de correo electrónico de los actores políticos involucrados, para establecer contacto con ellos y exigirles una representatividad política acorde con las posturas de los ciudadanos.

Según explica Castells (2012), tanto el uso de las redes sociodigitales como la ocupación del espacio público permiten la creación de redes "multimodales" que dan lugar a formas de reivindicación. En el estudio de caso analizado, dichas redes posibilitaron ampliar el alcance de la reivindicación y permitieron al individuo común generar emisiones de mensajes de manera autónoma a los medios tradicionales de comunicación y a los aparatos de control gubernamental. Estos 
mensajes viajaron a través de una red que en cada nodo de redistribución se multiplicó hasta adquirir alcances multitudinarios, provocando la autoorganización de una masa crítica, así como la emergencia de un sujeto colectivo cuyas acciones estuvieron en función de una esperanza reivindicativa frente a un sentimiento de indignación.

\section{Integración del estudio de caso}

Las protestas de los Malnacidos movilizaron una fuerza fundamental que estaba ahí en la sociedad sonorense, que se fue acumulando después de años de malestar social. Esa fuerza se podría llamar indignación. Muchas de las expresiones que circularon durante los momentos de la protesta aludían claramente a ello: injusticias, molestias, hartazgos, perjuicios, discriminaciones, indiferencias, impunidad, corrupción, prepotencia y autoritarismo.

Las protestas desencadenaron un proceso singular de construcción de sujetos en lucha, de una demanda por su autonomía, por ser individuos con derechos, actores de su propia vida. Las protestas de los Malnacidos fueron una irrupción en el espacio público, capaz de borrar las fronteras entre la vida privada y los poderes ejecutivo y legislativo. Fue un movimiento del todo político. Hombres y mujeres se posicionaron como ciudadanos que exigieron sus derechos, que cuestionaron de fondo, desde un posicionamiento político, la gestión pública del Estado y de los políticos en el gobierno.

El movimiento de los Malnacidos construyó una campaña ambigua en la que no se puede determinar quiénes fueron los autores de la reivindicación, para lo cual se plantean tres conjeturas: 1) la población local como grupo social, asumiéndose como un sujeto colectivo, desarrolló un movimiento social en su defensa en contra de una imposición gubernamental; 2) los actores políticos del partido opositor al que ocupaba la gubernatura del estado aprovecharon el estallido de la población y se valieron de esta situación para diseñar una serie de acciones a través de los manifestantes, con el fin de descalificar la administración estatal en curso; 3 ) un grupo reducido de activistas y luchadores sociales llamaron a las movilizaciones y más tarde perdieron la autoría de lo que se fue definiendo como un movimiento social con estructura propia. Dentro de la misma campaña, y gracias a la asesoría de Sonora Ciudadana, el movimiento fue capaz de definir con claridad un objeto específico y un adversario, al tiempo que se acercaron a diversas autoridades públicas para vincularlas a su campaña reivindicativa.

El movimiento desarrolló un repertorio extenso de manifestaciones y mítines. Se desarrolló la peculiaridad del uso de carros particulares en caravanas sobre las avenidas principales de la ciudad como gesto de rechazo al impuesto. Los Malnacidos diseñaron un pliego petitorio dirigido al Ejecutivo del estado, participaron en procesiones diversas, realizaron una vigilia constante en las sesiones del Congreso y recabaron firmas para solicitar un proceso jurídico en contra del gobernador Guillermo Padrés.

El movimiento se adjudicó una carga moral que legitimó sus protestas en contra del impuesto a la tenencia vehicular. Dados sus perfiles, los voceros tu- 
vieron gran empatía con la población: una joven madre de familia dedicada a las labores del hogar, un profesor jubilado de nivel medio, un hombre de familia, trabajador, y un joven estudiante de nivel superior. Esto se puede observar en el hecho de que el grueso de los manifestantes ponderó el valor de la familia en sus acciones, saliendo a manifestarse con sus hijos bebés, niños y adolescentes, autoafirmándose como personas honestas, trabajadoras, responsables y educadas.

Del mismo modo, la unidad se expresó a través de varios elementos simbólicos, en los que destaca el uso de memes humorísticos, el apelativo "soy sonorense malnacido", el logotipo de "no más impuestos”, usar la camiseta con ambas leyendas, portar orejas de burro en manifestaciones o decorar los carros con orejas de burro durante las caravanas, las calcomanías en los vehículos, el himno nacional y la canción Sonora querida. El compromiso se mantuvo durante cerca de cinco meses, haciéndole frente a múltiples declaraciones del gobernador y del alcalde de Hermosillo. Los manifestantes mostraron apoyo mutuo en los momentos en que los voceros recibieron amenazas de diversas maneras. Sin embargo, el compromiso se rompió en distintos puntos.

En enero y febrero de 2013 el movimiento de los Malnacidos se asumió como de tipo identitario, reconociendo que se había convertido en una fuerza unificada con símbolos propios de identificación colectiva. Más tarde, al reducir su objeto a una sola demanda en particular, se asumió como un movimiento programático, que diseñó de manera coherente sus acciones en relación con sus demandas. Finalmente, fue identificado por los mismos internautas, en los propios espacios digitales usados durante las protestas, como un movimiento social de posición que mantenía relaciones con ciertos actores políticos, compartiendo afinidades e intereses, de modo que las acciones del movimiento favorecían de cierta forma a un grupo de actores políticos en particular.

Derivado de una desconfianza profunda en los medios de comunicación tradicionales, el movimiento se valió de las redes para congregar a las personas indignadas, difundiendo las ideas de las protestas e influyendo en más personas para incrementar el número de manifestantes. Se utilizaron las redes también para legitimar los objetivos y las acciones del movimiento en otras partes del país y como una manera de competir contra los medios tradicionales (locales) de información.

El movimiento de los Malnacidos fue un medio de transformación social al influir en la eliminación del impuesto COMÚN y promover el voto en contra del Partido Acción Nacional en los comicios de 2015. La pérdida del compromiso tras los actos violentos provocados por grupos de choque contribuyó a la muerte del movimiento en un sentido de represión, al igual que la creación de la asociación Sonora Transparente lo hizo en un sentido de integración. Los voceros, como imagen del movimiento, se institucionalizaron en dicha asociación y perdieron la credibilidad del grueso de los manifestantes. Las imágenes de Rebeca Villanueva con diversos actores políticos y su nombramiento como directora de Cultura de Agua en el organismo operador de Agua de Hermosillo, durante la administración priista que sucedió al sexenio en el que el conflicto por la tenencia vehicular 
tuvo lugar, terminó por contribuir a la muerte del movimiento en un sentido de cooptación.

El ocaso del movimiento dio lugar a nuevas formas de vida institucional con la creación de la asociación civil Sonora Transparente. Ha dado lugar también a nuevos grupos seguidores de Rebeca Villanueva, quienes la vislumbran como un nuevo actor de la escena política local. Esto es observable en el apoyo manifestado a través de las redes sociodigitales. Asimismo el movimiento hizo de los procesos de subjetivación algo latente en los sonorenses, pues ahora existe una red de personas dispuestas a protestar en nuevas ocasiones en contra de situaciones que desfavorezcan su autonomía o atenten contra sus derechos. Esta red ha resurgido frente a posteriores situaciones de malestar social; también se ha pronunciado promoviendo candidaturas independientes en procesos electorales posteriores al conflicto.

Los voceros y otros integrantes del movimiento de los Malnacidos se relacionaron con algunos de los miembros de los partidos políticos PRD y PRI, quienes mostraron una capacidad de comprensión de las demandas sociales, usándolas a su favor como una herramienta de transformación social, presionando al partido en el poder y descalificándolo para la próxima contienda electoral. El movimiento se asumió como programático cuando se enfocó en un solo objetivo y desarrolló estrategias jurídicas adecuadas para su cumplimiento.

Los individuos perdieron la confianza en las instituciones, pues se sintieron traicionados cuando las acciones del Ejecutivo se mostraron contrarias a las promesas que realizó durante la campaña electoral. Tanto en la apropiación del espacio público mediante las manifestaciones, como a través de las redes sociodigitales, las promesas incumplidas de la campaña de Guillermo Padrés fueron evidenciadas. Los sonorenses protestaron porque perdieron credibilidad en el gobierno y por ello se movilizaron. Priorizaron el uso de las redes sociodigitales como un canal de información y comunicación al observar la escasa objetividad que los medios tradicionales de comunicación le daban al conflicto.

En el diálogo autónomo con otros internautas, así como en el acceso a la información de interés público, se generaron nuevas posibilidades de pensarse a sí mismo, a los otros y al contexto social de diversas maneras. Nuevas subjetividades emergieron en la horizontalidad comunicativa que las redes sociodigitales promovieron a escala regional, traspasando las categorías impuestas por la verticalidad de la información de los medios tradicionales locales.

En el reconocimiento de otros internautas y en la interacción con ellos fuera de los parámetros convencionales de interacción social, los ciudadanos ampliaron su criterio y complejizaron las formas de combinar el espacio público y la vida privada. Derivado del involucramiento en las protestas contra la tenencia vehicular a través de las redes sociodigitales, tales internautas devinieron en sujeto colectivo y manifestaron sus desacuerdos en diversas formas de resistencia, experimentando procesos de subjetivación en los que se dieron cuenta de que su contexto podía ser transformado. 


\section{Conclusiones}

Se encontró que las interacciones digitales pueden impulsar la emergencia de sujetos y favorecer procesos de subjetivación, debido a que la característica rizomática de las redes usadas por el movimiento de los Malnacidos permitió el encuentro de una diversidad de internautas que aportó múltiples formas de ver e interpretar el impuesto COMÚN y facilitó el intercambio de nuevas herramientas de visión, organización, convocatoria y coordinación de protestas. El intercambio de puntos de vista complejizó y transformó la manera en que los integrantes usuarios de redes sociodigitales se pensaban a sí mismos frente al impuesto de la tenencia vehicular. A partir de la conectividad, la interactividad, la vinculación y la comunicación digital con otros internautas y ciudadanos afectados por el impuesto a la tenencia vehicular, los integrantes del movimiento construyeron procesos de subjetivación y organizaron diferentes repertorios de acciones reivindicativas.

En la medida en que los internautas disponían de espacios de comunicación autónoma en el uso de redes sociodigitales, se volvieron capaces de organizarse, convocarse, coordinarse y deliberar, de tal forma que los procesos de subjetivación generados en las interacciones digitales devinieron en acción colectiva. Los internautas se asumieron como sujeto mediante diversas acciones colectivas, que diseñaron y propusieron desde las redes sociodigitales. Así, buscaron defender su autonomía e incrementar su nivel de participación en la transformación de su contexto social.

En el caso del movimiento de los Malnacidos, se llevó a cabo una serie de procesos de subjetivación derivados de una inconformidad social y expresados en las redes sociodigitales, de lo que se derivó un ejercicio de organización, convocatoria y coordinación de acciones colectivas, tales como: la ocupación del espacio público mediante manifestaciones, caravanas, mítines, la denuncia jurídica en contra de funcionarios públicos, la propuesta de un mecanismo alterno de recaudación fiscal y el amparo en contra de una ley que consideraban injusta. A través de estas seis acciones principales, defendieron su derecho a la participación ciudadana en decisiones de carácter público.

Las manifestaciones y el conjunto de protestas de los Malnacidos pueden ser considerados como procesos de subjetivación colectiva capaz de establecer puentes entre lo público y lo privado, en beneficio de la autonomía de los actores que se manifestaron en contra de la tenencia vehicular. Por lo tanto, el movimiento es un indicador de un proceso de modernización que buscó incrementar los medios de participación, pues esta lucha estaba dirigida contra la desvinculación entre la administración pública local y los habitantes de Hermosillo, la cual fue visible en la forma de hacer política del gobierno, en el abuso de autoridad.

Los Malnacidos, como movimiento social, buscaron establecer nuevos vínculos entre la vida privada y el espacio público. Promovieron el diálogo entre los actores políticos y los habitantes de la localidad, reclamaron ser reconocidos como ciudadanos con todos sus derechos. El diálogo se buscó para resolver un conflicto. Fue éste lo que dio vida y nutrió la protesta, pero el fin del movi- 
miento fue poner en claro que los habitantes de Sonora deseaban que se les respetaran sus derechos y que ningún actor político pudiera seguir ejerciendo una voluntad que atropelle la dignidad de los ciudadanos.

\section{Referencias}

Bonet, R. (8 de junio de 2011). El movimiento de los indignados ¿hasta cuándo resistirán? Replicante. Recuperado de http:// revistareplicante.com/el-movimiento-de-los-indignados/

Castells, M. (2012). Redes de indignación y esperanza. Los movimientos sociales en la era de internet. Barcelona: Alianza Editorial.

Esquivel, G. (10 de octubre de 2011). El mito de la tenencia y las olimpiadas. Animal Político. Recuperado de http://www.animalpolitico.com/blogueros-el-vaso-medio-vacio/2011/10/10/el-mito-de-la-tenencia-y-las-olimpiadas/

Galindo, J. (2006). Cibercultura. Un mundo emergente y una nueva mirada. México: Consejo Nacional para la Cultura y las Artes.

Hine, C. (2004). Etnografía virtual. Barcelona: Universidad Oberta de Catalunya.

Mattoni, A. (2013). Repertoires of communication in social movement processes. En B. Cammaerts, A. Mattoni y P. McCurdy (eds.), Mediation and Protest Movements (pp. 39-56). Bristol: Intellect.

Morales, F. (2014). El movimiento estudiantil \#YoSoy132. Antología hemerográfica (tesis de maestría en historia inédita). Universidad Iberoamericana, México.

Moreno, J. L. (2013). Crónicas de una protesta ciudadana y una movilización social. Inédito.

Pink, S., Horst, H., Postill, J., Hjorth, L., Lewis, T., y Tacchi, J. (2016). Digital Ethnography. Principles and Practice. Londres: Sage.

Ramos, J. (4 de julio de 2011). FCH anuncia eliminación total de tenencia en 2012. El Universal. Recuperado de http://archivo.eluniversal.com.mx/notas/777093.html

Rosagel, S. (24 de enero de 2013). Sonora, la rebelión de "los malnacidos": un movimiento de solo 14 días pone en jaque al gobierno de Padrés. Sin Embargo. Recuperado de http://www.sinembargo.mx/24-01-2013/502657

Tilly, C. (2010). Los movimientos sociales 1768-2008. Desde sus orígenes a Facebook. Barcelona: Egedsa.

Toret, J., Calleja, A., Marín, O., Aragón, P., Aguilera, M., y Lumbreras, A. (2013). Tecnopolítica: la potencia de las multitudes conectadas. El sistema red 15M, un nuevo paradigma de la política distribuida. Barcelona: Universidad Oberta de Catalunya.

Touraine, A. (2006). Crítica de la modernidad. México: Fondo de Cultura Económica.

Touraine, A. (2011). ¿Podremos vivir juntos? México: Fondo de Cultura Económica. 
Treré, E., y Barranquero, A. (2018). Tracing the roots of technopolitics: towards a North-South dialogue. En F. Sierra Caballero y T. Gravante (coords.), Networks, Movements and Technopolitics in Latin America. Critical Analysis and Current Challenges (pp. 43-63). Cardiff: Palgrave Macmillan.

Varón, E. (2012). El papel de las TICS en la Primavera Árabe. En AAVV (ed.): Manual de Promoción. Foro sobre la Eficacia del Desarrollo de las OSC. Bruselas.

Wieviorka, M. (2011). Una sociología para el siglo XXI. Barcelona: Universidad Oberta de Catalunya. 